\title{
Total serum cholesterol in relation to psychological
}

\section{correlates in parasuicide}

MALCOLM GARLAND, DARA HICKEY, AIDAN CORVIN, JEANETTE GOLDEN, PATRICIA FITZPATRICK, SEAN CUNNINGHAM and NOEL WALSH

Background Low cholesterol may act as a peripheral marker for parasuicide.

\begin{abstract}
Aims To examine the relationship between total serum cholesterol and psychological parameters in parasuicide.
\end{abstract}

Method Total serum cholesterol and self-rated scores for impulsivity, depression and suicidal intent were measured in 100 consecutive patients following parasuicide, pair-matched with normal and psychiatric control groups.

Results Backward, stepwise multiple regression analysis revealed a significantly lower mean cholesterol in the parasuicide population $(P<0.0 I)$. Across all groups there was an independent significant $(P<0.0$ I $)$ negative correlation between cholesterol and self-reported scores of impulsivity. No correlation existed between cholesterol and scores for depression or suicidal intent.

\section{Conclusions The data confirm} previous reports of low cholesterol in parasuicide. This is the first reported investigation of the construct of impulsivity in relation to cholesterol.We hypothesise that the reported increased mortality in populations with low cholesterol may derive from increased suicide and accident rates consequent on increased tendencies to impulsivity in these populations.

\section{Declaration of interest None.}

Debate has been ongoing in the field of psychiatry regarding the possible relevance of cholesterol to mental health (e.g. Hawton et al, 1993), largely in the light of several publications in the field of epidemiology in the early 1990s (e.g. Muldoon et al, 1990). In cohorts with low cholesterol excess mortality from traumatic death, including suicide, was reported. Gallerini et al (1995) published data from a controlled population of 331 parasuicides, and found a lower cholesterol level in this group. Enkelberg (1992) proposed that low, or lowered, central nervous system (CNS) cholesterol in synaptosomal membranes could decrease serotonin receptor expression. The association between decreased serotonin and parasuicide (Asberg et al, 1976), as well as disorders characterised by impulsivity and aggression, is well documented.

\section{METHOD}

\section{Subjects and exclusion criteria}

The index population (100 patients) was recruited from patients admitted consecutively to the psychiatric unit following any act of parasuicide/deliberate self-harm (DSH) requiring admission from the accident and emergency department. The following exclusion criteria were applied: age $<16$ or $>65$ years; significant $(>5 \mathrm{lb})$ weight loss in the month prior to admission; the presence of haemodynamic compromise or of any physical condition or treatment (e.g. special diets, hypocholesterolaemic agents) that may affect serum cholesterol level; the presence of abnormality on haematological, renal and liver function tests carried out routinely on all patients. Psychiatric exclusion criteria were: psychotic disorders; addiction; eating disorders; recent (within previous 6 weeks) commencement, or change in dosage, of psychotropic medication; administration of electroconvulsive therapy (ECT) in the previous 6 weeks.

Two control populations were recruited: normal $(n=100)$ and psychiatric $(n=100)$. These were pair-matched for age and gender with the index cases. The same relevant exclusion criteria were applied. The normal controls were recruited from the medical day ward on the morning of their elective admission for minor diagnostic or therapeutic procedures. The psychiatric controls were recruited from the out-patient psychiatric department. Patients with a prior history of DSH were excluded from these groups.

\section{Assessments}

Patients (DSH and psychiatric) were diagnosed according to ICD-10 research diagnostic criteria (World Health Organization, 1993) with the relevant Axis I and II diagnoses. In addition to standard demographic data, the following were documented: weekly alcohol intake, with cut-off points as defined by the Royal College of Psychiatrists' guidelines (1986): $\geqslant 21$ units per week for men and $\geqslant 14$ units per week for women; violence of the attempted DSH, classified as high (e.g. self-hanging) or low (e.g. self-poisoning); intoxication at the time of DSH; and the presence of a clear, acute (within the previous 24 hours) precipitating event for the DSH.

The following self-rated instruments were administered:

(a) The Suicide Intent Scale (SIS; Beck et al, 1974). This 15 -item scale is rated $0-2$ for each item, giving a total score range of $0-30$.

(b) The Beck Depression Inventory (BDI; Beck et al, 1961). This 21-item scale classifies depression as follows: $10-15=$ mild; 16-23=moderate; $24-63=$ severe.

(c) The Barratt Impulsivity Scale, version 11 (BIS-11; Barratt, 1994). The BIS11 is a 34 -item instrument designed to measure impulsivity. All items are answered on a four-point scale. Three sub-scales exist: attentional impulsivity (e.g. "I concentrate easily", "I get bored easily when solving thought problems"), motor impulsivity (e.g. "I do things without thinking", "I am self-controlled") and non-planning impulsivity (e.g. "I plan tasks carefully", "I finish what I start").

All of the above have documented satisfactory psychometric properties. 


\section{Cholesterol estimation}

Total serum cholesterol was measured on a Beckman Synchron CX7 analyser by an enzymatic timed end-point method (Allain et al, 1974). In this method, serum specimens are diluted 1:100 with reagents. The cholesterol esters are hydrolysed by the enzyme cholesterol esterase to yield free cholesterol and fatty acids. The free cholesterol is oxidised to cholesten-3-one and hydrogen pyroxide by another enzyme, cholesterol oxidase. Peroxidase then catalyses the reaction of hydrogen pyroxide with 4-aminoantipyrine and phenol to produce a coloured quinoneimine product (Trinder's reaction). The change in absorbence at $520 \mathrm{~nm}$ is proportional to the cholesterol concentration in the specimen. The fasting status of subjects was not recorded because the cholesterol level is not altered significantly by this (Cohn et al, 1988). Venous blood was drawn in the morning.

\section{Statistical analysis}

Comparisons between continuous variables in the three matched groups were made using analysis of variance (ANOVA) for paired samples. Variables were then entered into backward, stepwise multiple regression analysis; where necessary, continuous psychometric variables were subdivided into tertiles. The second principal analysis was within groups. Within each group, the association of cholesterol as a continuous variable with variables of interest was estimated using Pearson's correlation coefficient for continuous variables and the two-sided $t$-test for categorical variables. Factors significant on univariate analysis were entered into a backward, stepwise multiple regression model to determine independent factors. To facilitate analysis, axis I and II psychiatric diagnoses were both split into two groups: axis I disorders into depressive- (including adjustment disorder) and non-depressive-spectrum illnesses; axis II into impulsive- (dissocial and emotionally unstable) and non-impulsivespectrum personality disorders.

We next examined the index population with each control group separately, using backward stepwise logistic regression. Finally, we examined the association with variables of interest within male and female groups separately, with factors significant on univariate analysis entered into a backward, stepwise multiple regression model.

\section{RESULTS}

\section{Inter-group analysis}

Tables 1 and 2 contain the descriptive data: continuous and categorical. Table 1 contains the results of the ANOVA for paired samples for the continuous variables. There was an overall significant difference in mean cholesterol level between the three groups, with the
DSH group having the lowest mean level. All applicable psychological scores differed significantly between the three groups. The DSH group expressed the greatest level of depressive and impulsivity symptoms. As the standard deviations imply, there was a wide range of self-reported depressive symptomatology in the DSH and psychiatric groups and suicidal intent in the DSH group.
Table I Descriptive data with comparison of continuous variables between three paired groups using ANOVA for paired samples

\begin{tabular}{|c|c|c|c|c|}
\hline Variable (mean) & DSH patients & Normal controls & Psychiatric controls & $P$ value \\
\hline Cholesterol $\left(\mathrm{mmol} \mathrm{I}^{-1}\right)$ & $4.41(1.02)$ & $4.69(0.97)$ & $4.95(1.07)$ & 0.0003 \\
\hline Age (years) & $32.66(10.13)$ & $32.25(10.26)$ & $33.04(9.60)$ & NS \\
\hline $\mathrm{BDI}$ & $23.89(10.70)$ & $2.28(3.40)$ & $22.17(11.27)$ & 0.0001 \\
\hline BIS-II (total score) & $75.31(13.03)$ & $62.66(9.82)$ & $71.32(11.90)$ & 0.0001 \\
\hline Non-planning sub-scale & $29.15(6.04)$ & $24.49(4.49)$ & $27.10(5.42)$ & 0.0001 \\
\hline Motor sub-scale & $25.0 \mathrm{I}(5.28)$ & $21.23(4.48)$ & $23.97(5.35)$ & 0.0001 \\
\hline Attentional sub-scale & $21.25(3.97)$ & $17.04(3.53)$ & $20.40(3.63)$ & 0.0001 \\
\hline SIS & $10.31(6.69)$ & $N / A$ & $N / A$ & \\
\hline
\end{tabular}

Values in parentheses are standard deviations.

N/A, not applicable.

DSH, deliberate self-harm; BDI, Beck Depression Inventory; BIS-II, Barratt Impulsivity Scale, version II; SIS, Suicide Intent Scale.

Table 2 Descriptive data with comparison of categorical variables between three paired groups using ANOVA for paired samples

\begin{tabular}{|c|c|c|c|}
\hline Variable & DSH patients & Normal controls & Psychiatric controls \\
\hline Gender (male/female) & $30 / 70$ & $30 / 70$ & $30 / 70$ \\
\hline \multicolumn{4}{|l|}{ Marital status } \\
\hline Single & 63 & 57 & 60 \\
\hline Married & 19 & 39 & 33 \\
\hline Divorced/widowed & 18 & 4 & 7 \\
\hline Employed & 46 & 74 & 58 \\
\hline \multicolumn{4}{|l|}{ Social class } \\
\hline I & 4 & 5 & 2 \\
\hline II & 18 & 24 & 21 \\
\hline III & 32 & 44 & 49 \\
\hline IV & 13 & 20 & 20 \\
\hline V & 33 & 7 & 8 \\
\hline Alcohol intake (> guidelines') & 28 & 8 & 12 \\
\hline Previous DSH & 50 & $\mathrm{~N} / \mathrm{A}$ & $\mathrm{N} / \mathrm{A}$ \\
\hline Previous psychiatric history & 31 & $\mathrm{~N} / \mathrm{A}$ & 26 \\
\hline \multicolumn{4}{|l|}{ Violence of DSH } \\
\hline High & 89 & $\mathrm{~N} / \mathrm{A}$ & $N / A$ \\
\hline Low & II & & \\
\hline Acute precipitant & 51 & $\mathrm{~N} / \mathrm{A}$ & $\mathrm{N} / \mathrm{A}$ \\
\hline Intoxicated on admission & 46 & N/A & $\mathrm{N} / \mathrm{A}$ \\
\hline Axis I depressive spectrum & 74 & $\mathrm{~N} / \mathrm{A}$ & 76 \\
\hline Axis II impulsive spectrum & 16 & $\mathrm{~N} / \mathrm{A}$ & 0 \\
\hline
\end{tabular}

I. Royal College of Psychiatrists, 1986.

Values are percentage cases in each group.

N/A, not applicable.

DSH, deliberate self-harm. 
Table 3 Association between variables and cholesterol across the three groups $(n=300)$, adjusted for age and gender

\begin{tabular}{|c|c|c|c|c|c|}
\hline Variable & Variable sub-category & Number & Mean cholesterol $\left(\mathrm{mmol} \mathrm{I}^{-1}\right)$ & Adjusted F value' & $\begin{array}{l}\text { Adjusted } F \text { value for final } \\
\text { model }^{2}\end{array}$ \\
\hline \multirow[t]{3}{*}{ Group } & DSH & 100 & $4.41(1.02)$ & $29.57 * *$ & $28.76 * *$ \\
\hline & Normal & 100 & $4.69(0.97)$ & & \\
\hline & Psychiatric & 100 & $4.95(1.07)$ & & \\
\hline \multirow[t]{3}{*}{ Age (years) } & $16-26$ & 100 & $4.22(0.73)$ & $76.31 * *$ & $74.22 * *$ \\
\hline & $27-35$ & 101 & $4.76(1.07)$ & & \\
\hline & $>35$ & 99 & 5.07 (1.09) & & \\
\hline Male gender & & & & 0.94 & 0.91 \\
\hline Alcohol intake & & & & 1.29 & - \\
\hline \multirow[t]{5}{*}{ Social class } & I & II & $4.89(1.17)$ & 2.05 & - \\
\hline & II & 63 & $4.57(0.85)$ & $4.07^{*}$ & $3.94 *$ \\
\hline & III & 125 & $4.57(1.02)$ & II.24** & $10.93^{* *}$ \\
\hline & IV & 53 & $5.03(1.83)$ & $32.86 * *$ & $31.96 * *$ \\
\hline & V & 48 & $4.69(1.05)$ & 0.00 & - \\
\hline \multirow[t]{4}{*}{ Marital status } & Single & 179 & $4.50(1.01)$ & $58.33 * *$ & $56.73 * *$ \\
\hline & Married & 96 & $5.04(1.05)$ & $73.95^{* *}$ & $71.92 * *$ \\
\hline & Divorced & 22 & $4.59(0.89)$ & 0.82 & - \\
\hline & Widowed & 3 & $4.60(0.70)$ & 0.08 & - \\
\hline Employment status & & & & 0.68 & - \\
\hline \multirow[t]{2}{*}{ Previous history of DSH } & Yes & 50 & $4.50(1.20)$ & $8.42^{* *}$ & $8.81^{* *}$ \\
\hline & No & 250 & $4.72(0.99)$ & & \\
\hline Non-planning sub-scale & $0-24$ & 109 & $4.81(0.99)$ & $10.88 * *$ & $10.58 * *$ \\
\hline \multirow[t]{2}{*}{ (BIS-II) score } & $25-29$ & 92 & $4.67(1.07)$ & 0.09 & - \\
\hline & $>29$ & 99 & $4.56(1.07)$ & $9.49 * *$ & $9.23 * *$ \\
\hline \multirow[t]{3}{*}{ Motor sub-scale (BIS-II) score } & $0-20$ & 97 & $5.04(1.16)$ & $77.11 * *$ & $74.99 * *$ \\
\hline & $21-25$ & 103 & $4.51(0.84)$ & $18.86 * *$ & $18.35 * *$ \\
\hline & $>25$ & 100 & $4.51(1.01)$ & |8.82** & $10.58^{* *}$ \\
\hline Attentional sub-scale & $0-17$ & 96 & $4.74(1.03)$ & 1.77 & - \\
\hline \multirow[t]{2}{*}{ (BIS-II) score } & $|8-2|$ & 104 & $4.61(1.02)$ & 3.03 & - \\
\hline & $>21$ & 100 & $4.70(1.08)$ & 0.19 & - \\
\hline \multirow[t]{4}{*}{ BDI score } & $0-9$ & 118 & $4.65(0.97)$ & 0.03 & - \\
\hline & $10-15$ & 32 & $4.81(1.27)$ & 2.86 & - \\
\hline & $16-23$ & 61 & $4.83(1.00)$ & 2.83 & - \\
\hline & $24-63$ & 89 & $4.57(1.06)$ & 0.84 & - \\
\hline \multirow[t]{2}{*}{ Axis I depressive spectrum } & With & 150 & $4.75(1.12)$ & $6.48^{*}$ & $6.30 *$ \\
\hline & Without & 150 & $4.61(0.95)$ & & \\
\hline \multirow[t]{2}{*}{ Axis I non-depressive spectrum } & With & 50 & $4.45(0.89)$ & $13.84 * *$ & $13.46 * *$ \\
\hline & Without & 250 & $4.73(1.06)$ & & \\
\hline Axis II impulsive spectrum & With & 16 & $4.92(1.80)$ & $3.90 *$ & - \\
\hline Axis II non-impulsive spectrum & Without & 284 & $4.67(1.03)$ & 1.31 & - \\
\hline
\end{tabular}

Values in parentheses are standard deviations; $* P<0.05$ and $* * P<0.01$.

I. Adjusted for all variables listed.

2. Adjusted for all variables left in final model (including age and gender).

DSH, deliberate self-harm; BDI, Beck Depression Inventory; BIS-II, Barratt Impulsivity Scale, version II; SIS, Suicide Intent Scale.

Table 3 displays the results of the multiple regression analysis of categorical and continuous data to determine independent factors associated with cholesterol across the three groups. Group type (DSH, normal or psychiatric), older age, social class IV, being married, lower 'non-planning' and 'motor' scores on the BIS-11 and having a desperate diagnosis remained independently significantly positively associated with the level of cholesterol across the three groups $(n=300)$. A prior history of DSH, a medium or high motor sub-scale score on the BIS-11, a non-depressive diagnosis, being single and being from social classes II or III remained independently significantly negatively associated with the cholesterol level.

\section{Intra-group analysis}

The data were then analysed within each group. The association of cholesterol as a continuous variable with variables of interest 
Table 4 Associations between cholesterol and continuous variables in the three groups ( $r=$ Pearson's correlation coefficient)

\begin{tabular}{|c|c|c|c|c|c|c|}
\hline \multirow[t]{2}{*}{ Variable } & \multicolumn{2}{|c|}{ DSH patients } & \multicolumn{2}{|c|}{ Normal controls } & \multicolumn{2}{|c|}{ Psychiatric controls } \\
\hline & $r$ & $P$ & $r$ & $P$ & $r$ & $P$ \\
\hline Age & 0.29 & $<0.01$ & 0.32 & $<0.01$ & 0.38 & $<0.01$ \\
\hline BDI & 0.19 & 0.05 & 0.01 & 0.95 & -0.14 & 0.18 \\
\hline BIS-II (total score) & -0.01 & 0.92 & -0.19 & 0.06 & -0.09 & 0.33 \\
\hline Attentional sub-scale & -0.03 & 0.75 & -0.09 & 0.33 & 0.02 & 0.83 \\
\hline Motor sub-scale & -0.01 & 0.96 & -0.19 & 0.07 & -0.27 & 0.01 \\
\hline Non-planning sub-scale & 0.01 & 0.96 & -0.14 & 0.17 & 0.02 & 0.84 \\
\hline SIS & -0.7 & 0.51 & N/A & N/A & N/A & $\mathrm{N} / \mathrm{A}$ \\
\hline
\end{tabular}

N/A, not applicable.

DSH, deliberate self-harm; BDI, Beck Depression Inventory; BIS-II, Barratt Impulsivity Scale, version II; SIS, Suicide Intent Scale. was estimated for continuous variables (Table 4) and for categorical variables (Table 5). Factors significant on univariate analysis were entered into a multiple regression model to determine independent factors (Table 6).

In the correlational analysis (Table 4), age remained strongly positively related to cholesterol level in all three groups. In the DSH group, the BDI score just failed to reach statistical significance (positive correlation), whereas motor impulsivity in the psychiatric controls was significantly negatively related to cholesterol level. No relationship was observed between cholesterol and self-reported suicidal intent in the DSH group.

Table 5 Associations between cholesterol and categorical variables in each of the three patient groups (two-sided t-tests)

\begin{tabular}{|c|c|c|c|c|c|c|c|}
\hline \multirow[t]{2}{*}{ Variable } & & \multicolumn{2}{|c|}{ DSH patients } & \multicolumn{2}{|c|}{ Normal controls } & \multicolumn{2}{|c|}{ Psychiatric controls } \\
\hline & & Mean & $P$ & Mean & $P$ & Mean & $P$ \\
\hline \multirow[t]{2}{*}{ Gender } & Male & $4.18(0.69)$ & 0.07 & $4.85(0.94)$ & 0.27 & $4.90(0.98)$ & 0.79 \\
\hline & Female & 4.51 (1.12) & & $4.62(0.98)$ & & $4.96(1.12)$ & \\
\hline \multirow[t]{5}{*}{ Social class } & I & 4.45 (I.48) & 0.88 & $5.04(0.56)$ & 0.02 & $5.40(2.12)$ & 0.39 \\
\hline & II & $4.26(0.64)$ & & $4.58(0.93)$ & & $4.82(0.85)$ & \\
\hline & III & $4.36(0.98)$ & & $4.34(0.97)$ & & 4.81 (1.07) & \\
\hline & IV & $4.63(1.54)$ & & $4.98(0.78)$ & & $5.35(1.22)$ & \\
\hline & V & $4.45(0.96)$ & & $5.60(1.21)$ & & $4.85(0.92)$ & \\
\hline \multirow[t]{4}{*}{ Marital status } & Single & $4.25(0.93)$ & 0.15 & $4.56(0.93)$ & 0.08 & 4.72 (I.I2) & 0.03 \\
\hline & Married & $4.84(1.36)$ & & $4.93(0.98)$ & & $5.25(0.93)$ & \\
\hline & Separated & $4.56(0.85)$ & & $3.80(0.69)$ & & $5.55(0.49)$ & \\
\hline & Widowed & $4.20(0.14)$ & & $5.40(0.55)$ & & - & \\
\hline \multirow[t]{2}{*}{ Alcohol } & $<$ Guidelines ${ }^{\prime}$ & $4.37(0.94)$ & 0.54 & $4.69(0.98)$ & 0.93 & $4.96(1.09)$ & 0.62 \\
\hline & $>$ Guidelines $^{\prime}$ & $4.51(1.20)$ & & $4.66(0.81)$ & & $4.80(0.94)$ & \\
\hline \multirow[t]{2}{*}{ Previous DSH } & Yes & $4.50(1.24)$ & 0.39 & $\mathrm{~N} / \mathrm{A}$ & $\mathrm{N} / \mathrm{A}$ & N/A & $\mathrm{N} / \mathrm{A}$ \\
\hline & No & $4.32(0.74)$ & & & & & \\
\hline \multirow[t]{2}{*}{ Previous psychiatric history } & Yes & $4.46(1.11)$ & 0.38 & $\mathrm{~N} / \mathrm{A}$ & $\mathrm{N} / \mathrm{A}$ & $4.94(1.03)$ & 0.99 \\
\hline & No & $4.29(0.79)$ & & & & $4.94(1.17)$ & \\
\hline \multirow[t]{2}{*}{ Violence of DSH } & High & $3.98(0.5 I)$ & 0.02 & $\mathrm{~N} / \mathrm{A}$ & $\mathrm{N} / \mathrm{A}$ & N/A & $\mathrm{N} / \mathrm{A}$ \\
\hline & Low & $4.46(1.05)$ & & & & & \\
\hline \multirow[t]{2}{*}{ Acute precipitant } & Yes & $4.29(0.88)$ & 0.33 & $\mathrm{~N} / \mathrm{A}$ & $\mathrm{N} / \mathrm{A}$ & $\mathrm{N} / \mathrm{A}$ & $\mathrm{N} / \mathrm{A}$ \\
\hline & No & $4.51(0.20)$ & & & & & \\
\hline \multirow[t]{2}{*}{ Intoxicated on admission } & Yes & $4.27(0.88)$ & 0.22 & $\mathrm{~N} / \mathrm{A}$ & $\mathrm{N} / \mathrm{A}$ & $\mathrm{N} / \mathrm{A}$ & $\mathrm{N} / \mathrm{A}$ \\
\hline & No & $4.55(1.22)$ & & & & & \\
\hline \multirow[t]{2}{*}{ Axis I spectrum } & Depressive & $4.46(1.06)$ & 0.18 & $\mathrm{~N} / \mathrm{A}$ & $\mathrm{N} / \mathrm{A}$ & $5.03(1.07)$ & 0.17 \\
\hline & Non-depressive & $4.01(0.5 I)$ & & & & $4.69(1.03)$ & \\
\hline \multirow[t]{2}{*}{ Axis II spectrum } & Impulsive & $4.92(1.18)$ & 0.02 & $\mathrm{~N} / \mathrm{A}$ & $\mathrm{N} / \mathrm{A}$ & N/A & $\mathrm{N} / \mathrm{A}$ \\
\hline & Non-impulsive & $4.31(0.96)$ & & & & & \\
\hline
\end{tabular}

I. Royal College of Psychiatrists, 1986.

Values in parentheses are standard deviations.

N/A, not applicable.

DSH, deliberate self-harm. 


\begin{tabular}{|c|c|c|c|c|}
\hline & Variable & Adjusted parameter estimates ${ }^{1}$ & Adjusted parameter estimates for final model $\left.\right|^{2}$ & $P$ value \\
\hline \multirow[t]{5}{*}{ DSH patients } & Age & $0.03^{* *}$ & $0.03 * *$ & 0.005 \\
\hline & Violence of DSH & 0.57 & - & \\
\hline & BDI & 0.01 & - & \\
\hline & Axis I & 0.13 & - & \\
\hline & Axis II & $-0.54^{* *}$ & $-0.53 *$ & 0.047 \\
\hline \multirow{3}{*}{ Normal controls } & Social class & 0.12 & - & \\
\hline & BIS-II (total score) & -0.01 & - & \\
\hline & BIS-II motor sub-scale & -0.02 & - & \\
\hline \multirow[t]{2}{*}{ Psychiatric controls } & Age & $0.03 * *$ & $0.03 * *$ & 0.0003 \\
\hline & BIS-II motor sub-scale & $-0.04^{*}$ & $-0.04 *$ & 0.019 \\
\hline
\end{tabular}

I. Adjusted for all variables significant or nearly significant on multivariate analysis.

2. Adjusted for all variables left in final model.

DSH, deliberate self-harm; BDI, Beck Depression Inventory; BIS-II, Barratt Impulsivity Scale, version II; SIS, Suicide Intent Scale.

The results in Table 5 reveal a significantly lower mean cholesterol level in those who used a violent means of DSH, had a non-depressive-spectrum illness and a nonimpulsive-spectrum personality disorder. None of the other categorical variables was related to cholesterol.

The multivariate analysis of individual groups in Table 6 again confirms the independent association between age and cholesterol. Less highly significant associations existed between Axis II spectrum personality disorder (positive association for impulsive-spectrum disorders) in the DSH group and motor impulsivity in the psychiatric controls (negative association).

\section{Comparison of DSH group with each control group}

The DSH group was then compared with each control group individually. After backward stepwise logistic regression, the cholesterol level remained independently associated with group type when compared with the psychiatric control after adjusting for age and gender (odds ratio $=0.48$, $P<0.01)$. Similar analysis of the normal control group after adjustment failed to show a significant difference in cholesterol between the two groups.

\section{Analysis by gender}

Finally, the level of cholesterol was examined within each gender group. For males $(n=90)$, total BDI score $(P=0.04)$ and attentional $(P=0.01)$ and non-planning $(P=0.004)$ sub-scales of the BIS-11 were each negatively associated with cholesterol levels, whereas being unemployed and older were positively associated. After multivariate analysis, only non-planning impulsivity (negative association, $P=0.007$ ) and age (positive association, $P=0.0001$ ) were associated independently. A similar analysis in the female group $(n=210)$ revealed an independent (positive) association for increasing age only.

\section{DISCUSSION}

Our study sought to examine the association between cholesterol level and appropriate psychometric variables with two principal questions in mind. First, is there any difference in cholesterol level between the patient groups examined, and second, is there an association between cholesterol level and measures of 'suicidality', impulsivity and depression (reflecting hyposerotonergic function) within and across the groups? We appear to have found some answers to our two principal questions. First, there was a significant difference in mean cholesterol level between the three groups, with the parasuicide group having the lowest and the psychiatric controls the highest levels, with the normal controls intermediate. Second, we found that cholesterol and non-planning and motor sub-scale scores of self-reported impulsivity were significantly inversely related. The failure of the intra-group analysis to mirror the results of the paired analysis probably reflects the difference in statistical power (greater for the paired analysis) between the two methods: the double-control method of the study was primarily designed for paired analysis. This has the obvious advantages of shortening the recruiting time of the study to procure the same total population and having two disparate control groups, but it concomitantly makes within-group analysis less powerful. Analysis by gender revealed no association between impulsivity and cholesterol for women, but for men, considering their smaller number $90 v$. 210), a fairly strong association with nonplanning impulsivity was seen. Some findings are counter-intuitive. That no independent association existed between total BDI score and cholesterol, but did exist (negatively) for the presence of a depressive diagnosis is odd, as is the finding of a higher mean cholesterol in impulsivespectrum personality disorders, although only 16 patients had this diagnosis.

However, one needs to bear in mind the very large populations used in the epidemiological studies in this area (see below) in considering the findings of this more modestly sized study. The finding of a lower mean cholesterol in parasuicide accords with other published studies. By systematically examining cholesterol in relation to psychological correlates, our study has taken a further step in examining the relevance of this lipid to mental health.

\section{Low cholesterol and mortality}

Epidemiological evidence strongly suggests the existence of a J-shaped curve in relation to total cholesterol and mortality, and that the principal causes of mortality in the low 
cholesterol populations are trauma (road traffic accidents, homicide, etc.) and suicide. The largest study examining low cholesterol and mortality was that of Jacobs et al (1992), who pooled the results of 20 naturalistic cohort studies (total population over 600000 ) and found an excess mortality, in adults with lower cholesterol levels, from deaths due to non-cancer, non-cardiovascular causes and 'trauma' (including suicide, $P<0.001)$. This effect persisted after controlling for age, race, smoking, income and blood pressure. In 1990, Muldoon et al published a metaanalysis of six large cholesterol-lowering primary prevention trials that found no overall reduction in mortality between treatment and non-treatment groups $(n=27847, P=0.004)$. It was found that an excess of violent and non-accidental deaths, including suicide, in the treatment groups compensated for the reduced cardiac mortality. On the basis of these results, it appears reasonable to hypothesise that low cholesterol as a trait, or as the desired result of cholesterol-lowering treatment, may in some way influence CNS function or act as a peripheral marker for factors governing predisposition to death by trauma and suicide.

\section{Cholesterol and the CNS}

Enkelberg (1992), aware that peripheral cholesterol exchanges freely with that in the CNS, proposed that, as a principal component of neuronal membranes, the concentration of cholesterol could determine the availability of the serotonin receptor and its transporter by inducing changes in their quaternary structure. He refers to in vitro work that has demonstrated just this: cholesterol, by increasing the microviscosity of mouse synaptosomal membranes, greatly enhanced serotonin uptake intracellularly (Heron et al, 1980). This hypothesis provides a model to address not only the phenomenon of excess suicides in those with low cholesterol, but also the increased mortality from accidents and trauma. Hyposerotonergic function is not just linked to depression, parasuicide and completed suicide, but it is also linked to aggression and impulsivity (Coccaro, 1989), which are crucial antecedents to accidents, trauma, parasuicide and suicide (Romanov et al, 1994).

\section{Cholesterol in psychiatric populations}

The results of studies examining cholesterol in different psychiatric disorders have often been conflicting. For depressive disorders the findings have been inconclusive and possibly confounded by weight loss secondary to depression (Law et al, 1994). The literature on cholesterol and disorders of impulsivity and aggression is also equivocal. Virkkunen (1983) did, however, find lower mean cholesterol levels in a population of homicidal offenders and, in later studies, arsonists and those with antisocial personality disorder and aggressive conduct disorder. As reviewed by Wardle (1995), cholesterol-lowering drugs in five prospective studies showed no effects on depression or aggression. However, all of the parasuicide studies have revealed significantly lower total cholesterol concentrations in their study populations. Of these studies, Kunugi et al (1997) $(n=99)$, Golier et al (1995) ( $n=650)$ and our own all controlled for potential confounders such as weight loss.

\section{Cholesterol and serotonin}

The evidence to support a cholesterolserotonin link is also divided, but somewhat less so. Anderson et al (1990) found that a 3-week low-calorie diet reduced plasma tryptophan and increased prolactin secretion in response to a tryptophan challenge. Steegmans et al (1996) reported a significant correlation between plasma serotonin and cholesterol level in a population of 100 men with low cholesterol but not in a reference population with normal cholesterol. Terao et al (1997) found a significant positive correlation between serum cholesterol and prolactin response to the serotonin agonist $m$-chlorophenylpiperazine in ten healthy volunteers. However, Delva et al (1996) found no relationship between cholesterol, plasma tryptophan and $d$-fenfluramineinduced prolactin release (a probe of central serotonergic function) in 40 subjects, 20 of whom were on cholesterol-lowering treatment. Similarly, Ringo et al (1994) examined the cholesterol-serotonin relationship in 84 humans and found only an insignificant correlation between total serum cholesterol and cerebrospinal fluid (CSF) 5-hydroxy-indoleacetic acid (5HIAA). With animal studies, Kaplan et al (1994) found lower 5-HIAA concentrations and more aggressive and less affiliative behaviour in 17 cynomolgus monkeys fed a low-cholesterol diet compared with animals on normal rations.

\section{Other lipids and the CNS}

The focus of recent research on lipids has not limited itself to cholesterol. Studies are now finding important correlates between another lipid fraction obtained exclusively from diet - the essential fatty acids (EFAs) - and the same psychological parameters associated with cholesterol and serotonin (i.e. depression, impulsivity, hostility, etc.) (see Horrobin, 1998, for review). Although cholesterol is an important component of neuronal membrane phospholipid, so too are the EFAs. The two most common cerebral EFAs, arachidonic acid and docosohexaenoic acid (DHA), make up $15 \%$ of the dry weight of the brain. Small changes in membrane EFA composition can produce large quaternary conformational changes in proteins, which include receptors and ion channels. Large variations in behaviour due to differing dietary EFA intake are therefore possible. One illustration is the strong correlation that has been described recently between fish consumption and the incidence of major depression across the world $(r=-0.84 ; \quad P<0.005) \quad$ (Hibbeln, 1998). Fish is a principal source of DHA. Hibbeln et al (1998) found a strong correlation between CSF serotonin metabolites and EFAs, particularly DHA $(P<0.0002)$, in a population of alcoholics. This finding also applied to normal controls. It may be that cholesterol, in previous studies, was acting as a 'surrogate marker' for EFAs. This possibility is currently being examined.

\section{REFERENCES}

Allain, C. C., Poon, L. S., Chan, C. S. G., et al (1974) Enzymatic determination of total serum cholesterol. Clinical Chemistry, 20, 470-475.

Anderson, I. M., Parry-Billings, M., Newsholme, E. A., et al (1990) Dieting reduces plasma tryptophan and alters brain 5-HT function in women. Psychological Medicine, 20, 785-79l.

Asberg, M., Traskman, L. \& Thoren, P. (1976) 5-HIAA in the cerebrospinal fluid: a biochemical suicide predictor. Archives of General Psychiatry, 33, 1193-1197.

Barratt, E. S. (1994) Impulsiveness and aggression. In Violence and Mental Disorder: Developments in Risk Assessment (eds J. Monahan \& H. J. Steadman), pp. 61-79. Chicago: University of Chicago Press.

Beck, A. T., Ward, C. H., Mendelson, M., et al (196I) An inventory for measuring depression. Archives of General Psychiatry, 4, 56I-57I.

_ , Herman, J. \& Schuyler, D. (1974) Development of suicidal intent scales. In The Prediction of Suicide (eds A. T. 
Beck, H. L. P Resruk \& D. J. Lettieri), pp. 45-48. Bowie, MD: Charles Press.

Coccaro, E. F. (1989) Central serotonin and impulsive aggression. British Journal of Psychiatry, $\mathbf{I 5 5}$ (suppl. 8), $52-62$

Cohn, J. S., McNamara, J. R. \& Schaefer, E. J. (1988) Lipoprotein cholesterol concentrations in the plasma of human subjects as measured in the fed and fasted states. Clinical Chemistry, 34, 2456-2459.

Delva, N. J., Mathews, D. R. \& Cowen, P. J. (1996) Brain serotonin (5-HT) neuroendocrine function in patients taking cholesterol lowering drugs. Biological Psychiatry, 39, 100-106.

Enkelberg, H. (1992) Low serum cholesterol and suicide. Lancet, 339, 727-729.

Gallerini, M., Manfredini, R., Caracciolo, C., et al (1995) Serum cholesterol concentrations in parasuicide. British Medical Journal, 310, 1632-1636.

Golier, J. A., Marzuk, P. M., Leon, A. C., et al (1995) Low serum cholesterol level and attempted suicide. American Journal of Psychiatry, I52, 419-423.

Hawton, K., Cowen, P., Owens, D., et al (1993) Low serum cholesterol and suicide. British Journal of Psychiatry, 162, 818-825.

Heron, D. S., Shinitzky, M., Herschkowitz, M., et al (1993) Low serum cholesterol and suicide. British Journal of Psychiatry, 162, 818-825.

Heron, D. S., Shinitzky, M., Herschkowitz, M., et al (1980) Lipid fluidity markedly modulates the binding of serotonin to mouse brain membranes. Proceedings of The National Academy of Science, USA, 77, 7463-7467.

Hibbeln, J. R. (1998) Fish consumption and major depression. Lancet, i, 1213 .

__, Linnoila, M., Umhau, J. C., et al (1998) Essential free fatty acids predict metabolites of serotonin and dopamine in CSF of normal controls and early and late onset alcoholics. Biological Psychiatry, 44, 235-242.

Horrobin, D. F. (1998) Fatty acids, aggression and impulsivity. In Neurobiology and Clinical Views on Aggression and Impulsivity (eds M. Maes \& E. F. Coccao), pp. 109-123. Chichester: Wiley

Jacobs, D., Blackburn, H., Higgins, M., et al (1992) Report of the conference on low blood cholesterol: mortality associations. Circulation, 86, 1046-1060.

Kaplan, J. R., Shively, C. A., Fontenot, M. B., et al (1994) Demonstration of an association among dietary cholesterol, central serotonergic activity, and socia behavior in monkeys. Psychosomatic Medicine, 56 479-484.

Kunugi, H., Takei, N., Aoki, H., et al (1997) Low serum cholesterol in suicide attempters. Biological Psychiatry, 4I, 196-200.

Law, M. R., Thompson, S. G. \& Wald, N. J. (1994)

Assessing possible hazards of reducing serum cholesterol. British Medical Journal, 308, 373-379.

\section{CLINICAL IMPLICATIONS}

Low cholesterol may indicate at-risk populations for parasuicide/completed suicide.

- Cholesterol may act as a marker for serotonin in the central nervous system and for its associated psychological constructs.

- Caution may need to be exercised with over-zealous cholesterol lowering in the population.

\section{LIMITATIONS}

Cholesterol was the only lipid fraction measured.

Results of the paired analysis did not mirror those of individual groups.

The total study population was relatively small.

MALCOLM GARLAND, MRCPsych, DARA HICKEY, MRCPsych, Department of Psychiatry, St Vincent's University Hospital, Dublin; AIDAN CORVIN, MRCPsych, St Patrick's Hospital, Dublin; JEANETTE GOLDEN, MRCPsych, Department of Psychiatry, St Vincent's University Hospital, Dublin; PATRICIA FITZPATRICK, FFPHMI, Department of Public Health Medicine and Epidemiology, University College, Dublin; SEAN CUNNINGHAM, PhD, Department of Biochemistry, St Vincent's Hospital, Dublin; NOEL WALSH, FRCPsych, Department of Psychiatry, St Vincent's University Hospital, Dublin, Ireland

Correspondence: Malcolm Garland, Department of Psychiatry, St Vincent's University Hospital, Elm Park, Dublin 4, Ireland. Tel. : 00353 | 209447I ; fax: 00353 | 2837556; e-mail: mgarland@svherc.ucd. ie

(First received 30 June 1999, final revision 16 December 1999, accepted 16 December 1999)

Muldoon, M. R., Manuck, S. B. \& Mathews, R. M. (1990) Lowering cholesterol concentrations and mortality: a quantitative review of the Primary Prevention Trials. British Medical Journal, 30I, 309-314.

Ringo, D. L., Lindley, S. E., Faull, K. F., et al (1994) Cholesterol and serotonin seeking a possible link between blood cholesterol and CSF 5-HIAA. Biological Psychiatry, 35, 957-959.

Romanov, K., Hatakka, M., Keskinen, E., et al (1994) Self-reported hostility and suicidal acts, accidents, and accidental deaths: a prospective study of 21,443 adults aged 25 to 59. Psychosomatic Medicine, 56, 328-336.

Royal College of Psychiatrists (1986) Alcohol: Our Favourite Drug. London: Tavistock.

Steegmans, P. H. A., Fekkes, D., Hoes, A. W., et a (1996) Low serum cholesterol concentration and serotonin metabolism in men. British Medical Journal, $\mathbf{3 1 2}, 221$.

Terao, T., Yoshimura, R., Ohmori, O., et al (1997) Effect of serum cholesterol levels on mCPP-evoked neuroendocrine responses in healthy subjects. Biological Psychiatry, 4I, 974-978.

Virkkunen, M. (1983) Serum cholesterol levels in homicidal offenders. Neuropsychobiology, 10, 65-69.

Wardle, J. (1995) Cholesterol and psychological well being. Journal of Psychosomatic Research, 39, 549-562.

World Health Organization (1993) The ICD-10 Classification of Mental and Behavioural Disorders: Diagnostic Criteria for Research. Geneva: WHO. 